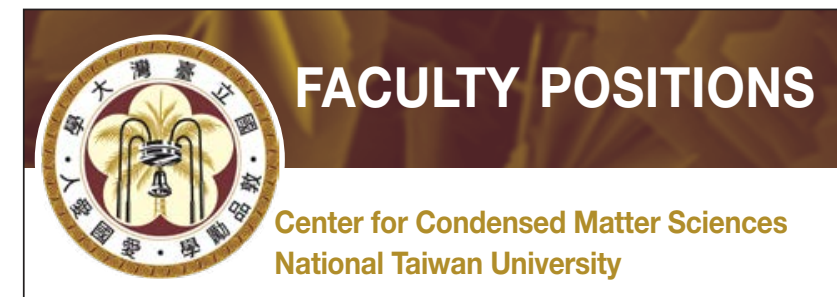

The Center for Condensed Matter Sciences, as a premiere research center at the National Taiwan University, has immediate openings for tenure-track faculty positions. Rank of faculty positions will match the candidate's qualifications. Applicants with excellent credentials in cutting edge condensed matter research fields, such as emerging materials or advanced spectroscopic and microscopic techniques, in both fundamental and applied aspects, will be considered.

Applicants should send resume, publication list, research plans, and three letters of recommendation to:

Director, Dr. Michitoshi Hayashi

Center for Condensed Matter Sciences

National Taiwan University

Taipei 106, Taiwan

Center Assistant: Wei-Lin Chou

Email: cwli1828@ntu.edu.tw

Phone: 02-3366-5201

Fax: 02-2365-5404

Closing date for applications is November 30, 2018.

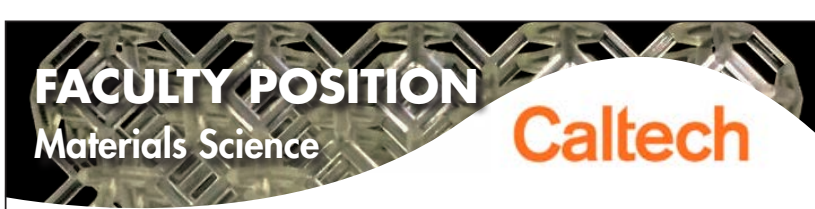

The California Institute of Technology invites applications for a Materials Science tenure-track Assistant Professor position in the department of Applied Physics and Materials Science of the Division of Engineering and Applied Science. Materials science research at Caltech focuses on the application of scientific and engineering principles to understanding synthesis-structureproperties relationships in materials, including a diverse array of applications.

Candidates in all areas of materials science or related fields are invited to apply, including (but not limited to) those with a primary research focus on discovery, synthesis and processing of materials. Candidates are expected to make strong commitments to excellence in research, teaching and mentoring. Initial appointments will be made at the assistant professor level for four years and are contingent upon completion of the $\mathrm{PhD}$ degree.

Please submit your online application at https://applications.caltech. edu/jobs/matsci. Applications must include a brief cover letter, curriculum vitae, relevant publications, a description of proposed research, and a statement of teaching interests. Also required are three letters of recommendation, and instructions will be given for submission when you apply online.

The position will remain open until filled, however, applications completed by December 1, 2018 will be assured of receiving full consideration.

We are an equal opportunity employer and all qualified applicants will receive consideration for employment without regard to race, color, religion, sex, sexual orientation, gender identity, or national origin, disability status, protected veteran status, or any other characteristic protected by law.

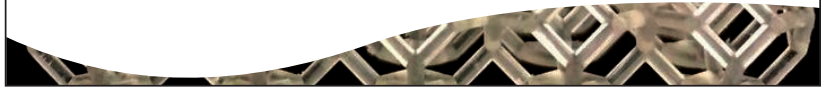

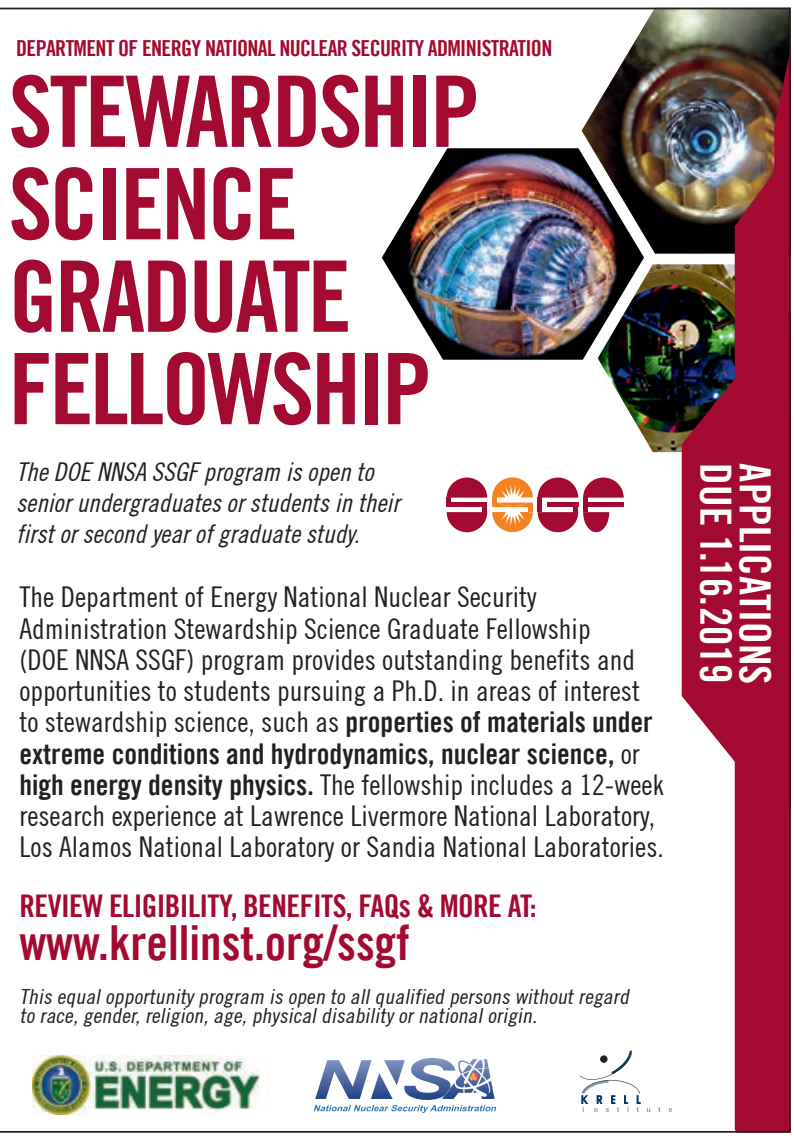

MATERIALS SCIENCE AND ENGINEERING Faculty Positions - Open Rank

University of Illinois at Urbana-Champaign

The Department of Materials Science and Engineering (MatSE) at the University of Illinois at Urbana-Champaign is seeking to fill multiple tenured or tenure-track faculty positions in all ranks. Candidates with research interests in the broad areas of biological materials, metals, and computational soft materials are strongly encouraged to apply. Faculty members in the department are expected to initiate and sustain a vigorous research program. Candidates are expected to demonstrate a strong commitment to undergraduate and graduate teaching, and to diversity, equity, and inclusion through research, teaching, and service. Please visit the website https://matse.illinois.edu/about/matse-careers to view the position description and application instructions.

Applications received prior to December 9, 2018 will receive full consideration.

The University of Illinois conducts criminal background checks on all job candidates upon acceptance of a contingent offer. Illinois is an EEO Employer/Vet/Disabled www.inclusiveillinois. illinois.edu and committed to a family-friendly environment (http://provost.illinois.edul faculty-affairs/work-life-balance).

\section{? ILLINOIS}

Materials Science \& Engineering COLLEGE OF ENGINEERING 